\title{
Antiviral Therapy for Varicella Zoster Virus (VZV) and Herpes Simplex Virus (HSV)-Induced Anterior Uveitis: A Systematic Review and Meta-Analysis
}

OPEN ACCESS

Edited by:

Claudia Fabiani,

University of Siena, Italy

Reviewed by:

Maria Vittoria Cicinelli, San Raffaele Scientific Institute

(IRCCS), Italy

Beatrice Gallo,

Moorfields Eye Hospital, NHS Foundation Trust, United Kingdom

*Correspondence:

Vishali Gupta

vishalisara@yahoo.co.in vishalisara@gmail.com

${ }^{\dagger}$ These authors share first authorship

Specialty section:

This article was submitted to Ophthalmology,

a section of the journal

Frontiers in Medicine

Received: 26 March 2021 Accepted: 07 June 2021 Published: 02 July 2021

Citation:

Testi I, Aggarwal K, Jaiswal N,

Dahiya N, Thng ZX, Agarwal A,

Ahuja A, Duggal M, Kankaria A, Ling

Ho S, Chee S-P, Westcott M,

Pavesio C, Agrawal R and Gupta V (2021) Antiviral Therapy for Varicella

Zoster Virus (VZV) and Herpes Simplex Virus (HSV)-Induced Anterior Uveitis: A Systematic Review and Meta-Analysis. Front. Med. 8:686427.

doi: 10.3389/fmed.2021.686427
Ilaria Testi ${ }^{1+}$, Kanika Aggarwal ${ }^{2 \dagger}$, Nishant Jaiswal ${ }^{3}$, Neha Dahiya ${ }^{2}$, Zheng Xian Thng ${ }^{4}$, Aniruddha Agarwal' ${ }^{2}$, Alka Ahuja ${ }^{2}$, Mona Duggal' ${ }^{2}$, Ankita Kankaria ${ }^{5}$, Su Ling Ho ${ }^{4}$, Soon-Paik Chee ${ }^{6,7,8,9}$, Mark Westcott ${ }^{1}$, Carlos Pavesio ${ }^{1}$, Rupesh Agrawal ${ }^{1,4,6,7,9,10}$ and Vishali Gupta ${ }^{2 *}$

${ }^{1}$ Department of Uveitis, Moorfields Eye Hospital, NHS Foundation Trust, London, United Kingdom, ${ }^{2}$ Advanced Eye Centre, Post-Graduate Institute of Medical Education and Research (PGIMER), Chandigarh, India, ${ }^{3}$ Department of Telemedicine, Postgraduate Institute of Medical Education and Research, Chandigarh, India, ${ }^{4}$ National Healthcare Group Eye Institute, Tan Tock Seng Hospital, Singapore, Singapore, ${ }^{5}$ Department of Community and Family Medicine, All India Institute of Medical Sciences (AIIMS), Bathinda, India, ${ }^{6}$ Singapore Eye Research Institute, Singapore, Singapore, ${ }^{7}$ Singapore National Eye Centre, Singapore, Singapore, ${ }^{8}$ Department of Ophthalmology, National University of Singapore, Singapore, Singapore, ${ }^{9}$ Duke National University of Singapore Medical School, Singapore, Singapore, ${ }^{10}$ Lee Kong Chian School of Medicine, Nanyang Technological University, Singapore, Singapore

Topic: Herpes simplex virus (HSV) and varicella zoster virus (VZV) are the most common ocular pathogens associated with infectious anterior uveitis. Currently, there are a number of antiviral agents administered to treat viral anterior uveitis (VAU). However, there is no consensus or guidelines about the most appropriate approach leading for the best treatment outcomes with fewer ocular complications.

Clinical Relevance: To perform a systematic review and meta-analysis of the efficacy of different antiviral therapies in the management of anterior uveitis secondary to HSV and VZV.

Methods: We searched PubMed, Web of Science, CINAHL, OVID, and Embase up to January 2020. Randomized trials, non-randomized intervention studies, controlled before and after studies and observational studies assessing the effect of oral and or topical treatments for VAU were considered. Data extraction and analysis with evaluation of the risk of bias in the included trials were performed.

Results: Oral acyclovir demonstrated a statistically significant good treatment outcome in the management of VZV anterior uveitis (vs. placebo) (OR 0.26, 95\% $\mathrm{Cl}$ 0.11-0.59), but did not have similar effect in HSV anterior uveitis (OR 0.47, 95\% Cl 0.15-1.50). In the treatment of VZV anterior uveitis, there was significant superiority of oral acyclovir-7 day course-over topical acyclovir (OR 4.17, 95\% Cl 1.28-13.52). Whereas, there was no significant superiority of one of the following treatment regimens over the others: topical acyclovir over topical corticosteroids (OR $1.86,95 \% \mathrm{Cl} 0.67-5.17)$, and oral acyclovir-7 day course-over oral acyclovir-14 day course-(OR 0.21, 95\% Cl 0.01-4.50) or oral valaciclovir (OR 1.40, 95\% Cl 0.48-4.07). 
Conclusion: Treatment of HSV and VZV anterior uveitis is currently based on individual experiences and limited literature, largely due to weak clinical trial evidence in this regard. Our results highlight the existence of a substantial gap in our evidence base. This finding might contribute to future research studies to ascertain the role of different antiviral therapies in the treatment of VAU.

Systematic Review Registration: PROSPERO registration number: CRD420202 00404.

Keywords: viral anterior uveitis, iritis, herpes simple virus, varicella zoster virus, herpes zoster ophtalmicus, antiviral therapy, acyclovir, valaciclovir

\section{BACKGROUND}

Viral anterior uveitis (VAU) is the most common form of infectious uveitis, accounting for more than $10 \%$ of all cases of anterior uveitis (1). Different members of the herpes virus family, including herpes simplex virus (HSV) and varicella zoster virus (VZV), are considered for the differential diagnosis when a viral etiology is suspected.

The diagnosis is mostly clinical (2-4). The presence of herpetic dermatitis, including vesicles occurring at the border of the eyelids and the zoster vesicular rash, or dendritic keratitis can provide a strong corroborative evidence for the diagnosis, but these findings are often absent. The presumptive diagnosis is thus based on ocular features, including unilateral involvement, reduced corneal sensation, keratic precipitates, iris atrophy and rise in intraocular pressure, with a course of the disease that is commonly recurrent (2-4). However, considering the overlap between clinical features suggestive of HSV and VZV anterior uveitis, once a viral etiology is suspected, polymerase chain reaction (PCR)-based analysis of aqueous humor sample may be used by the clinicians for confirming the diagnosis (5-8). The detection of the pathogen allows a more targeted therapy with the aim of limiting further spread of the virus and avoiding secondary tissue damage.

Treatment management of VAU is tailored to the virus and to the clinical immune response that the pathogen induces (9). Hence, therapeutic regimen usually includes antiviral medications (systemic and/or topical) in combination with topical inflammatory agents, commonly corticosteroids (1-3, 10-23). Cycloplegics and/or intraocular pressure lowering eye drops are the adjunctive therapy based on individual patient's clinical condition. Different antiviral agents for varying duration have been used in the treatment of VAU, including acyclovir and valacyclovir (1-3, 10-23).

To gain insight into the effectiveness of different therapeutic strategies and to propose the most appropriate treatment strategy for VAU, high-quality data collection or a welldesigned randomized controlled trial is warranted. The objective of this systematic review and meta-analysis is hence to assess and compare the effectiveness of antiviral therapies, administered alone or in combination with other agents, in the management of anterior uveitis secondary to HSV and VZV. Cytomegalovirus (CMV) has not been considered for the purpose of this analysis.

\section{METHODS}

The study protocol investigating the role of antiviral therapy for VZV and HSV induced anterior uveitis can be found at PROSPERO, international database of prospectively registered systematic reviews (registration number: CRD42020200404). The study was performed in accordance to the PRISMA (Preferred Reporting Items for Systematic Reviews and MetaAnalyses) guidelines. The PRISMA checklist is provided in Supplementary Data Sheet 1.

The inclusion criteria were:

\section{Participants}

Acute or chronic cases of viral anterior uveitis, caused by HSV or VZV, diagnosed on the basis of clinical criteria with or without confirmation by Goldmann-Witmer coefficient (GWC) or polymerase chain reaction (PCR) were included. Other inclusion criteria were: any age group (children and adults), either gender, any race and ethnicity, irrespective of the immune status, who received antiviral medications, either topical or systemic, including acyclovir, valacyclovir, famciclovir, ganciclovir, and valganciclovir.

\section{Types of Studies}

a. Randomized trials which assess the effect of oral and or topical treatments for viral anterior uveitis.

b. Non-randomized intervention studies and controlled beforeafter studies in addition to observational studies (including prospective and retrospective cohort and case-control studies, cross-sectional studies).

c. Studies that include subsets of relevant participants if the data for the relevant subsets are reported separately (in such cases, we planned to include only the data for the relevant subsets).

Case reports, letter to editors (not reporting cases), narrative reviews, and correspondence (such as editorials) were excluded. 

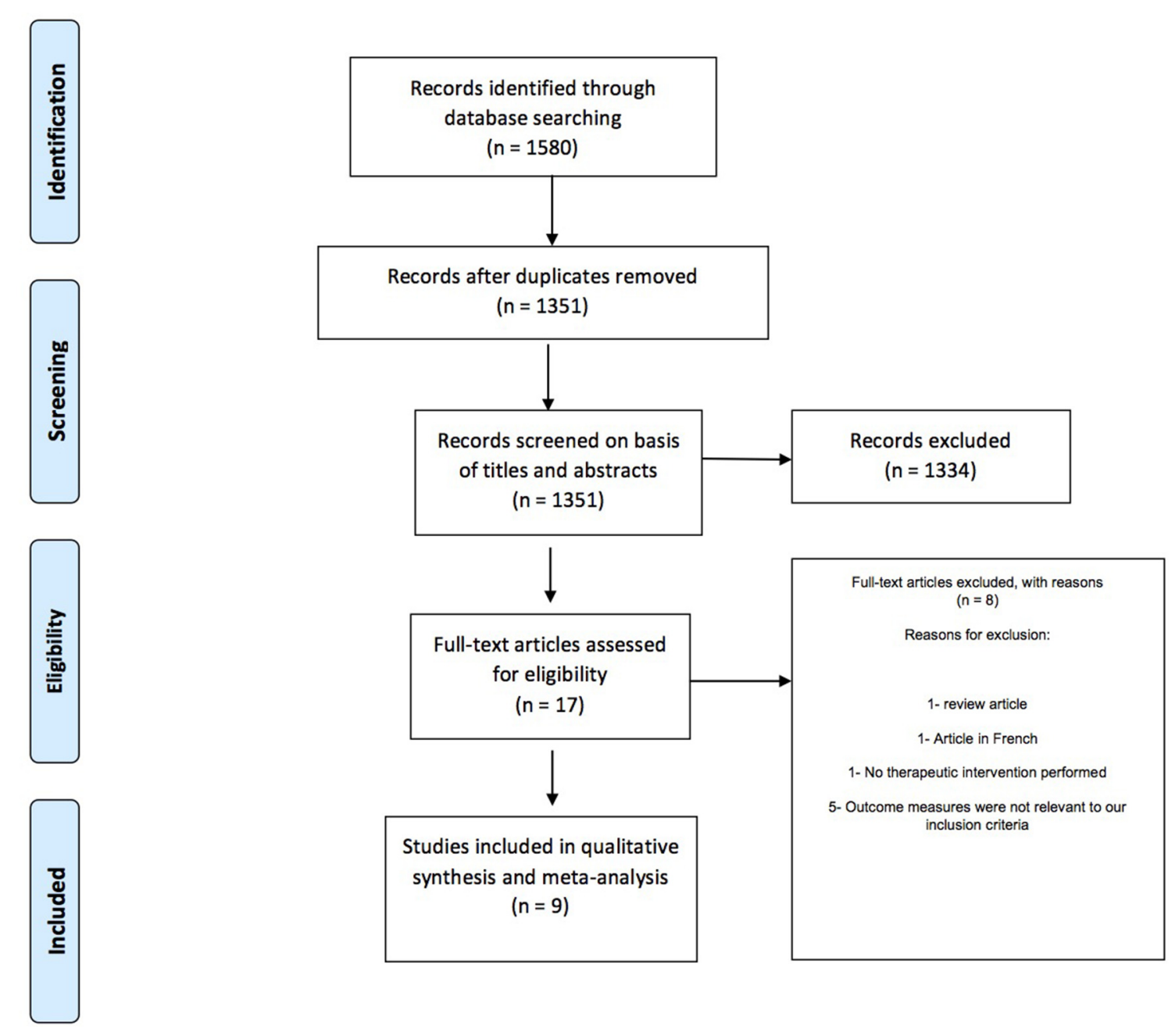

FIGURE 1 | PRISMA flowchart showing study screening and selection process.

\section{Types of Outcome Measure Primary Outcome Measure}

Number of patients with treatment failure as per the criteria defined in the included studies such as persistence or worsening of ocular inflammation, development of ocular inflammation, development of viral epithelial keratitis or epithelial defect, persistent rise in intraocular pressure despite maximally tolerated medical therapy, discontinuation of treatment due to an adverse reaction and voluntary withdrawal from study.

\section{Secondary Outcome Measures}

- Time-to-quiescence, defined as the duration from the presentation/recurrence of anterior uveitis to the time when zero cells were noted in the anterior chamber

- Time-to-recurrence, defined as the duration between achieving quiescence and the next episode

- Change in number of uveitis attacks before and after therapy, defined as mean number of uveitis recurrence/month of follow-up/patient
- Reduction of anti-glaucoma medications and antiinflammatory eye drops, defined as reduction in the number of intraocular pressure-lowering medications and in the frequency of steroid eye drops applications, respectively.

\section{Search Methods for Identification of Studies}

A systematic literature search of electronic databases i.e., PubMed, Web of Science, CINAHL, OVID, and Embase was performed by 2 independent reviewers. The searches included literature up to 27th August 2020. Publications in English language, or those which had English language translation were included in the analysis. The search strategy is provided in Supplementary Data Sheet 2.

\section{Data Collection and Analysis \\ Selection of Studies}

The duplicate articles were removed and screening of titles and abstracts was performed by two independent reviewers (IT and VG). Full text screening was done for articles which were 
not excluded and manuscripts which fit the inclusion criteria were used for data extraction. Any discrepancies were resolved through discussion with a third reviewer (RA) who acted as an arbiter. The screening and selection process has been described in a PRISMA flowchart (Figure 1).

\section{Data Extraction}

Two reviewers (IT and KA; both fellowship trained uveitis specialists) extracted the data independently on pre-piloted structured forms related to study setting, study design, demographic details of patients, etiology of viral anterior uveitis, various interventions or treatment/s given, duration of treatment, outcomes, adverse reactions to interventions and recurrences of disease. Discrepancies if any, were settled after discussion with a third reviewer (NJ).

\section{Assessment of Risk of Bias in Included Studies}

The risk of bias in each included study was assessed using Cochrane's "Risk of bias" tool (Higgins 2011). The tool assesses the biases introduced on the basis of various domains such as inadequacies in random sequence generation, allocation concealment, blinding of participants and study personnel, blinding of outcome assessments, reporting of incomplete outcome data and selective reporting. The review authors judged each of these criteria to have a low, unclear or high risk of bias.

\section{Measures of Treatment Effect}

For dichotomous data, we used odds ratios (OR) and presented these with 95\% confidence intervals (CIs). We used Revman 5.4 and Stata 14 software for meta-analysis.

\section{Assessment of Heterogeneity}

Heterogeneity was judged from both clinical and statistical perspectives. Clinical heterogeneity was assessed on the basis of the similarities of study participants, intervention protocols and outcome measures. The evaluation of statistical heterogeneity included visual inspection, and consideration of the $\mathrm{Chi}^{2}$ test and the $\mathrm{I}^{2}$ statistic. The following interpretation of $\mathrm{I}^{2}$ was applied:

- 0-40\%: might not be important;

- 30-60\%: may represent moderate heterogeneity;

- 50-90\%: may represent substantial heterogeneity;

- 75-100\%: considerable heterogeneity.

\section{Assessment of Reporting Bias}

We were unable to construct funnel plots (plotting trial effects against inverse standard errors of effects) to assess for reporting biases as planned, as $<10$ studies were available for all outcomes included in the meta-analysis.

\section{Data Synthesis}

Data was pooled from similar studies using inverse-variance fixed-effects method. Wherever it was inappropriate to pool data and meta-analysis was not possible, we presented the data in tables for illustrative purposes and a narrative synthesis was done.

\section{RESULTS}

\section{Results of the Research}

Our literature search retrieved a total of 1,580 articles out of which 229 articles were removed as duplicates (Figure 1). The titles and abstracts of the remaining 1,351 articles were screened and irrelevant articles were excluded. Full text screening was done for 17 studies which were assessed on the basis of our inclusion criteria. Eight studies were excluded for being unable to fulfill the inclusion criteria $(2,11,12,21,24-27)$, and the remaining 9 studies were included in this systematic review $(13-20,23)$. The characteristics of the included studies are listed in Table 1 (study details and population demographics) and Table 2 (diagnosis, intervention, outcome).

\section{Risk of Bias in Included Studies}

The risk of bias for various domains has been explained in Figures 2, 3 and the section below.

\section{Allocation \\ Random Sequence Generation (Selection Bias)}

We assessed two studies as at low risk of selection bias due to stratified randomization used as details describing a satisfactory method were provided $(13,20)$. We judged the remaining seven as at unclear risk of bias for this domain as they did not mention the method of randomization $(14-19,23)$.

\section{Allocation Concealment (Selection Bias)}

We evaluated one study to be at low risk of bias for this domain as studies concealed the allocations satisfactorily (20). We rated the remaining eight studies to have an unclear risk of bias as they did not report on allocation concealment (13-19, 23).

\section{Blinding}

Blinding of Participants and Personnel (Performance Bias)

We judged seven studies to be at unclear risk of performance bias as blinding of participants and personnel was not mentioned (14-19, 23). We rated the remaining two studies at low risk of performance bias as studies concealed the blinding of participants and personnel satisfactorily $(13,20)$.

\section{Blinding of Outcome Assessment (Detection Bias)}

We rated one study at high risk of bias as it was not completely blinded (20). We rated the remaining eight studies to be at unclear risk of detection bias as they did not mention blinding (13-19, 23).

\section{Incomplete Outcome Data}

We judged three studies with attrition of more than $15 \%$ to be at high risk of bias for this domain $(13,16,18)$. We considered four studies to be at low risk of attrition bias as attrition was much lower $(14,15,19,20)$. We judged the remaining study to be at unclear risk of attrition as it did not report on attrition (23). 
TABLE 1 | Study details and population demographics.

\begin{tabular}{|c|c|c|c|c|c|c|c|c|c|c|}
\hline $\mathbf{S} / \mathbf{N}$ & References & Study design & Origin & Sample size & $\begin{array}{l}\text { No. of patients } \\
\text { who received } \\
\text { antiviral } \\
\text { treatment }\end{array}$ & $\begin{array}{l}\text { Type of antiviral } \\
\text { treatment }\end{array}$ & Control group & No. of control & $\begin{array}{l}\text { Age (years); } \\
\text { mean }\end{array}$ & $\begin{array}{l}\text { Male gender } \\
(\%)\end{array}$ \\
\hline 1 & $\begin{array}{l}\text { The Herpetic Eye } \\
\text { Disease Study } \\
\text { Group (20) }\end{array}$ & $\begin{array}{l}\text { Multicentre, controlled } \\
\text { clinical trial }\end{array}$ & USA & 50 & 22 & Oral Acyclovir & Placebo & 28 & 53 & $38 \%$ \\
\hline 2 & $\begin{array}{l}\text { Wilhelmus et al. } \\
\text { (23) }\end{array}$ & Clinical trial & USA & 260 & 73 & Oral acyclovir & $\begin{array}{l}\text { Placebo; topical } \\
\text { corticosteroids }\end{array}$ & $187(49+138)$ & Not reported & Not reported \\
\hline 3 & $\begin{array}{l}\text { Marsh and Cooper } \\
\text { (18) }\end{array}$ & $\begin{array}{l}\text { Double-masked, } \\
\text { randomized trial }\end{array}$ & UK & 83 & 57 & Topical acyclovir & $\begin{array}{l}\text { Topical } \\
\text { corticosteroids }\end{array}$ & 26 & Not reported & Not reported \\
\hline 4 & $\begin{array}{l}\text { McGill and } \\
\text { Chapmen (19) }\end{array}$ & Controlled trial & UK & 40 & 20 & Topical acyclovir & $\begin{array}{l}\text { Topical } \\
\text { corticosteroids }\end{array}$ & 20 & 71 & $33.3 \%$ \\
\hline 5 & Cobo et al. (13) & $\begin{array}{l}\text { Prospective, } \\
\text { longitudinal, } \\
\text { randomized, } \\
\text { double-masked, } \\
\text { placebo-controlled trial }\end{array}$ & USA & 71 & 36 & Oral acyclovir & Placebo & 35 & Not reported & $53.5 \%$ \\
\hline 6 & Colin et al. (14) & $\begin{array}{l}\text { Multicentre, } \\
\text { randomized, } \\
\text { double-masked study }\end{array}$ & France & 110 & $110(54+56)$ & $\begin{array}{l}\text { Oral acyclovir (54); } \\
\text { oral valaciclovir (56) }\end{array}$ & Not reported & Not reported & $\begin{array}{l}62 \text { in the acyclovir } \\
\text { treated group and } \\
58 \text { in the } \\
\text { valaciclovir } \\
\text { treated group }\end{array}$ & $42.5 \%$ \\
\hline 7 & $\begin{array}{l}\text { Harding and } \\
\text { Porter (15) }\end{array}$ & Placebo controlled trial & UK & 42 & 23 & Oral acyclovir & Placebo & 19 & $\begin{array}{l}62.1 \text { in the } \\
\text { acyclovir treated } \\
\text { group and } 70.6 \text { in } \\
\text { the placebo } \\
\text { group }\end{array}$ & $32.6 \%$ \\
\hline 8 & $\begin{array}{l}\text { Hoang-Xuan et al. } \\
\text { (16) }\end{array}$ & $\begin{array}{l}\text { Bicentric, prospective, } \\
\text { randomized, double- } \\
\text { masked trial }\end{array}$ & $\begin{array}{l}\text { France, } \\
\text { Switzerland }\end{array}$ & 86 & $86(41+45)$ & $\begin{array}{l}\text { Oral acyclovir } 7 \text { day } \\
\text { course ( } 41 \text { ); oral } \\
\text { acyclovir } 14 \text { day } \\
\text { course ( } 45 \text { ) }\end{array}$ & Not reported & Not reported & $\begin{array}{l}50.5 \text { in } 7 \text { day } \\
\text { course group and } \\
56.6 \text { in } 14 \text { day } \\
\text { course group }\end{array}$ & $46.5 \%$ \\
\hline
\end{tabular}

$9 \quad$ Neoh et al. (17) Multicentre, open UK randomized trial

Topical acyclovir

(26); oral acyclovir

Not reported

Not reported

64.6

Not reported 


Etiology
Presumed
HSV

$\begin{array}{lc} & \text { Diagnosis } \\ \text { Diagnosis } & \begin{array}{l}\text { Ocular } \\ \text { manifestations }\end{array}\end{array}$

Local/systemic Patients
investigations

\section{Intervention}

Controls

Oral acyclovir, 400 mg, 5

Presence of at least Iridocyclitis; active Serum

$\begin{array}{ll}\text { The Herpetic } & \text { Presumed } \\ \text { Eye Disease } & \text { HSV } \\ \text { Study Group } & \\ \text { (20) } & \end{array}$

one of the following: non-necrotizing

(1) history

stromal keratitis;

antibodies to

consistent with

intraocular pressure

previous ocular $30 \mathrm{~mm} \mathrm{Hg}$ or more;

HSV disease, (2) no epithelial keratitis

presence of

concomitant

stromal keratitis

consistent with HS

as the cause, or (3)

the presence of

serum antibodies to

HSV in the absence

of other identifiable

causes of

iridocyclitis

to HSV

clinical findings,

epithelial keratitis or

epithelial defect

Not reported

(n)

Oral acyclovir two $200 \mathrm{mg}$ capsules, 5 times daily for weeks + prednisolone 6 times daily for 1 week, 4 for 1 week, then 6 times daily daily for 1 week, then once for 1 week, 4 times daily for 1 daily for the fifth week; at the week, twice daily for 1 week, sixth week, prednisolone then once daily for the fifth phosphate $0.125 \%$ used 4 week; at the sixth week, time daily for 1 week, then prednisolone phosphate twice daily for the next week, $0.125 \%$ used 4 time daily for then once daily for the final 3 1 week, then twice daily for weeks + topical trifluridine 4 the next week, then once times daily for 3 weeks, then the next week, then once times daily for 3 weeks, the
daily for the final 3 weeks $+\quad$ twice daily for 7 weeks; or topical trifluridine 4 times daily placebo eye drops - dose and for 3 weeks, then twice daily frequency as per

for 7 weeks

then twice daily for 7 weeks

$2.7 \%$ in topical corticosteroids and Oral acyclovir treated group; $6.5 \%$ in topical $2.0 \%$ in topical placebo treated group

necrotizing stromal keratitis and no 政 ancillary signs by 2 weeks after entry into the trial or over any 3 consecutive weeks; a 2-step or greater increase in cells in the anterior chamber; persistent iridocyclitis of $3+$ cells or more for 2 consecutive weeks; decrease in visual acuity of 4 or more lines on (HSV) than $1.0 \mathrm{~mm}$ in $\mathrm{eng}$ an: intracl dect more more than $35 \mathrm{mmHg}$ for at least 1 week despite maximally tolerated medical therapy: development of new active ocular HSV disease when off treatment; development of an adverse reaction attributable to trial
medications; use of a topical or systemic corticosteroid or antiviral agent other than the trial medications; patient decision to withdraw

Occurrence of HSV epithelial keratitis 
TABLE 2 | Continued

S/N References

Diagnosis

Outcome

\begin{tabular}{llllll}
\hline Etiology Diagnosis & Ocular & Local/systemic & Patients & Controls & Criteria for treatment failure
\end{tabular}
investigations

Cooper (18) VZV herpes zoster

Episcleritis; scleritis; Not reported

Acyclovir ointment $3 \% \pm$

Placebo ointment +

Failure to control intraocular inflammation

$70 \%$ in the topical keratitis: nummula

dexamethasone $0.1 \%$

acyclovir treated

disciform, sclero;

group; $53.8 \%$ in

iritis

treated group; $40.7 \%$

in topical acyclovir and

topical corticosteroids

treated group

$4 \quad$ McGill and Presumed Based on clinical Epithelial lesion; Chapmen VZV ground, backed up stromal lesion;

PCR on skin (19) by viral isolation eitis: scleritis when skin vesicles

lesions when

$5.9 \%$ in topical

acyclovir treated

group; $5.3 \%$ in topical were stll presnt

5 Cobo et al. Presumed Skin lesions of (13) VZV herpes zoster

Episcleritis; scleritis; Not reported dendritiform

ophthalmicus keratitis; stroma

keratitis; corneal

scarring/

vascularization;

vascularization;
anterior uveitis

keratic precipitates;

6 Colin et al. Presumed Skn iris atrophy

Skin lesions of

Episcleritis;

Not reported

Acyclovir ointment 5 times a Be

tamethasone $0.1 \% 5$ times Recurrence of ocular involvement

Skin vesicles
present

Oral acyclovir $200 \mathrm{mg} 3$

Placebo 3 capsule 5 times

capsule 5 times daily for 10 daily for 10 days

Progression of dermatologic or ocular

group days

disease during the acute treatment phase

$16.6 \%$ in oral acyclovir treated group; 51.

dendritic ulcer;

stromal keratitis;

ophthalmicus

uveitis; elevated

intraocular pressure

Harding and Presumed Skin lesions of Porter (15) VZV herpes zoster

Sclerokeratitis;

stromal keratiris;

aneterior uveitis

ophthalmicus

8 Hoang-Xuan Presumed Skin lesions of

et al. (16) VZV herpes zoster

superficial keratitis

Not reported

superficial keratitis;

Not reported

ophthalmicus

oedema; anterior

stromal infiltrates;
anterior uveitis

9 Neoh et al. Presumed Skin lesions of

Episcleritis;

Not reported

herpes zoster sclerokeratitis;

keratitis; anterior

uveitis

Valaciclovir $1,000 \mathrm{mg} 3$ times Not reported daily for 7 days or acyclovir

$800 \mathrm{mg} 5$ times daily for 7

days

Development Of Anterior Uveitis As Intraocular Complication

$17 \%$ in oral acyclovir treated group; $13 \%$ in group

\section{acyclovir $800 \mathrm{mg} 5$}

times daily

Placebo capsule 5 times dall

cyclovir $800 \mathrm{mg} 5$ times daily Not reported

or 7 days or for 14 days

oral acyclovir $800 \mathrm{mg} 5$ times Not reported daily for 7 days or acyclovir

ointment for 7 days 


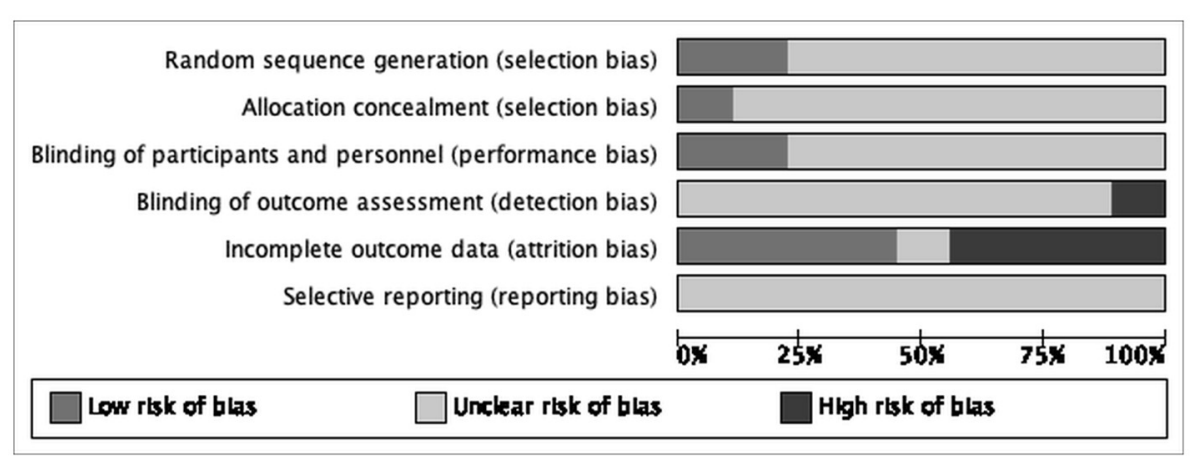

FIGURE 2 | Risk of bias graph: review authors' judgements about each "Risk of bias" item presented as percentages across all included study.

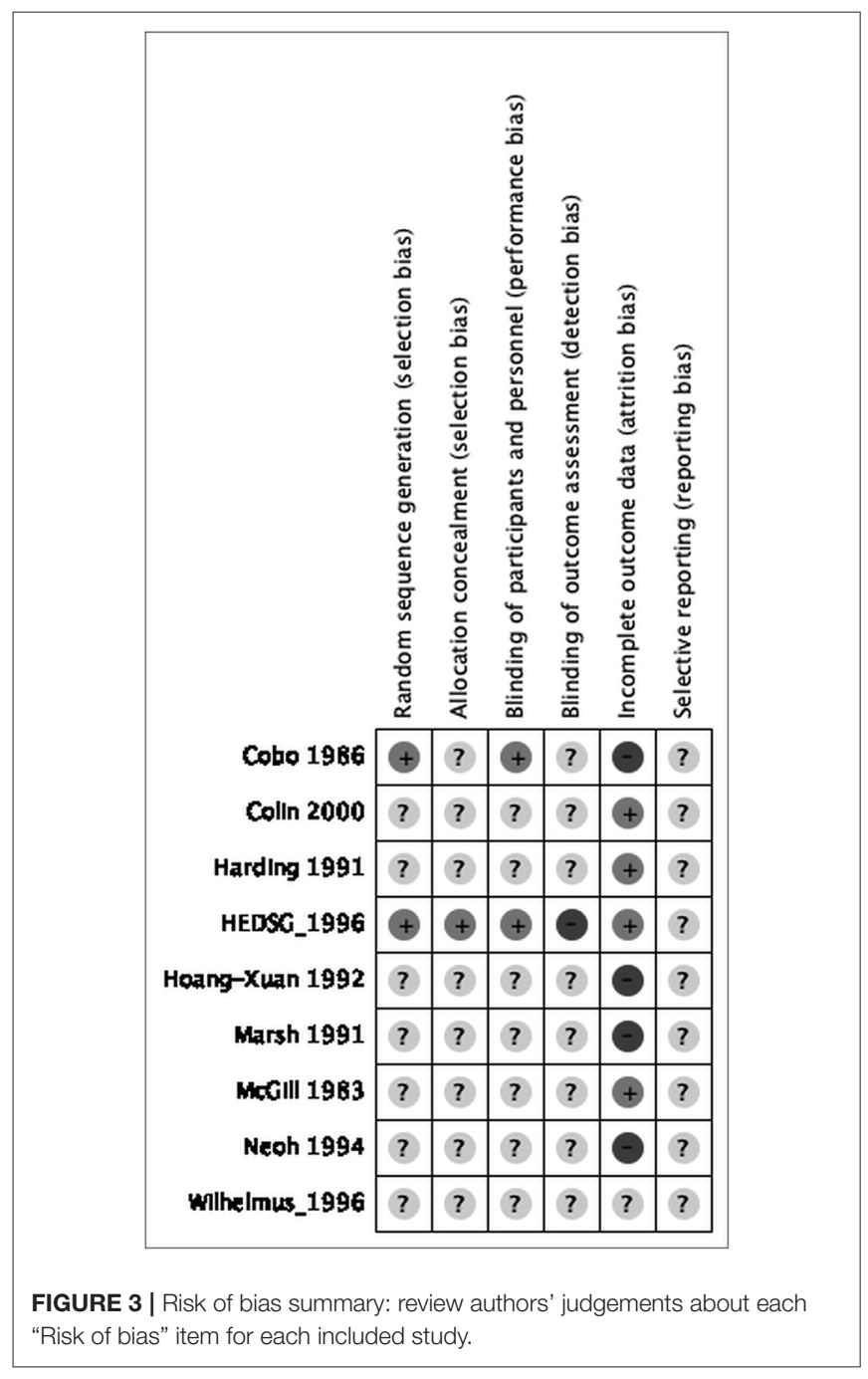

\section{Selective Reporting}

All nine studies were rated as unclear risk of reporting bias since no protocol is available to be compared to the respective published reports to identify any unreported outcomes (13-20, 23).

\section{Effects of Interventions Primary Outcome-Treatment Failure}

\section{Oral Acyclovir vs. Placebo}

Two studies reported on the number of treatment failure in HSV anterior uveitis patients treated with oral acyclovir (10 week course) vs. placebo $(20,23)$. The forest plot (Figure 4) does not show any significant superiority of oral acyclovir over placebo (OR 0.47, 95\% CI 0.15-1.50). Two other studies reported on the number of treatment failure in herpes zoster ophthalmicus (HZO) patients developing anterior uveitis treated with oral acyclovir (10 day course) vs. placebo $(13,15)$. The forest plot (Figure 5) shows significant superiority of oral acyclovir over placebo (OR $0.26,95 \%$ CI 0.11-0.59).

\section{Oral Acyclovir 7 vs. 14 Day Course}

One study reported on the number of treatment failures in HZO patients developing anterior uveitis treated with oral acyclovir 7 day course vs. 14 day course (16). The forest plot does not show any significant superiority of one duration of treatment over the other (OR 0.21, 95\% CI 0.01-4.50) (Table 3).

\section{Oral Acyclovir vs. Oral Valaciclovir}

One study reported on the number of treatment failures in HZO patients developing anterior uveitis treated with oral acyclovir (7 day course) vs. oral valaciclovir (14). The forest plot does not show any significant superiority of oral acyclovir over oral valaciclovir (OR 1.40, 95\% CI 0.48-4.07) (Table 3).

\section{Topical Acyclovir vs. Oral Acyclovir}

One study reported on the number of treatment failures in $\mathrm{HZO}$ patients developing anterior uveitis treated with topical acyclovir vs. oral acyclovir (7 day course) (17). The forest plot does show significant superiority of oral acyclovir over topical acyclovir (OR 4.17, 95\% CI 1.28-13.52) (Table 3).

\section{Topical Acyclovir vs. Topical Corticosteroids}

Two studies reported on the number of treatment failures in VZV anterior uveitis patients treated with topical acyclovir vs. 


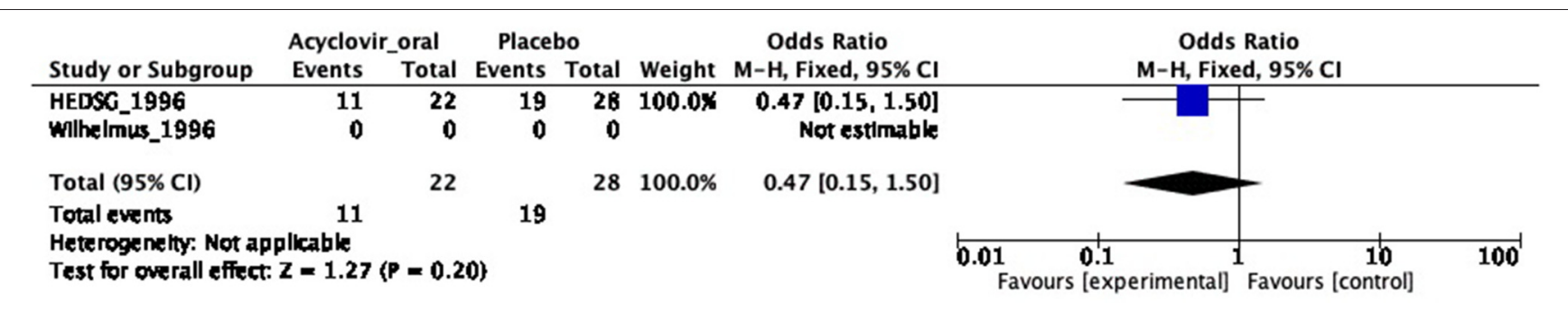

FIGURE 4 | Forest plot comparing treatment failure in herpes simplex virus anterior uveitis patients treated with oral acyclovir vs. placebo.

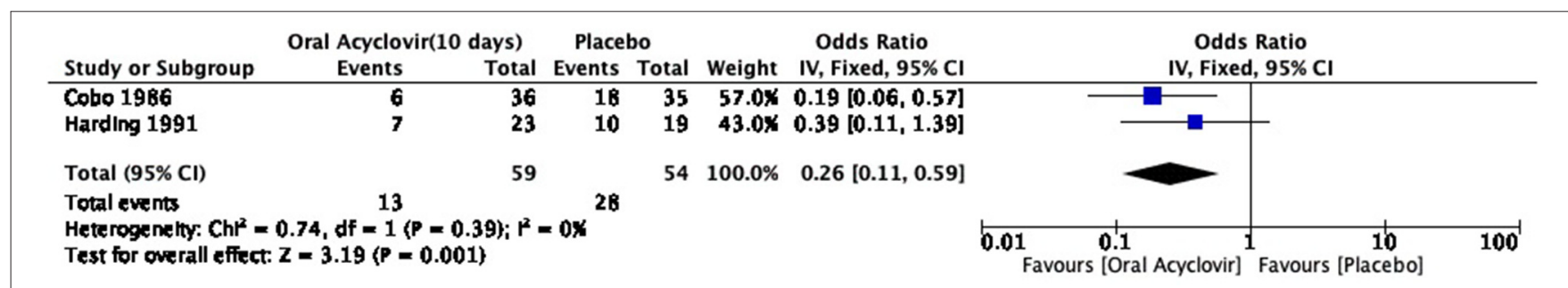

FIGURE 5 | Forest plot comparing treatment failure in herpes zoster ophthalmicus patients developing anterior uveitis treated with oral acyclovir vs. placebo.

TABLE 3 | Results of comparing treatment failure in herpes zoster ophthalmicus patients treated with Oral Acyclovir 7 vs. 14 Day Course, Oral Acyclovir vs. Oral Valaciclovir, and Topical Acyclovir vs. Oral Acyclovir.

\begin{tabular}{lc}
\hline Study & Odds Ratio (IV, Fixed, 95\% CI) \\
\hline Hoang-Xuan et al. (16) & $0.21(0.01,4.50)$ \\
Colin et al. (14) & $1.40(0.48,4.07)$ \\
Neoh et al. (17) & $4.17(1.28,13.52)$ \\
\hline
\end{tabular}

topical corticosteroids $(18,19)$. The forest plot (Figure 6) does not show any significant superiority of topical acyclovir over topical corticosteroids (OR 1.86, 95\% CI 0.67-5.17).

One study analyzed the rate of recurrence of HSV anterior uveitis among patients treated with oral acyclovir vs. placebo (33.3 and 22.2\%, respectively) (20), whereas, two studies reported on patients with VZV anterior uveitis experiencing recurrences after treatment with topical acyclovir vs. topical corticosteroids (from 0 to $18.7 \%$, and from 31.8 to $63 \%$, respectively) $(18,19)$.

Results related to adverse effects of systemic antiviral treatment regimen are available for oral acyclovir only and analyzed in four studies $(14-16,20) .4 .5-52.1 \%$ of patients experienced side effects $(15,20)$. Recurrences of uveitis attacks and adverse events to systemic antiviral medications are described in Table 4.

\section{DISCUSSION}

This study analyzed the occurrence of treatment failure in HSV and VZV anterior uveitis and ocular complications in herpes zoster ophthalmicus in patients treated with different antiviral therapies, administered alone or in combination with other agents, including corticosteroids. The review included nine randomized controlled trials (RCTs). Systematic search of scientific literature revealed that only two studies were specifically tailored to analyse whether the well-established and widely used systemic treatment approach with acyclovir was effective in HSV anterior uveitis $(20,23)$. Only two studies reported on the evidence for the use of topical acyclovir in VZV ocular inflammation $(18,19)$; whereas, five studies analyzed the effectiveness of systemic or topical acyclovir in preventing ocular complications from herpes zoster ophthalmicus (13, 15-17, 22). In addition, a significant research gap has been identified, as no data have been published since 2000. In particular, our forest plots (analysis 1-3) were constructed on old studies, the most recent of which was dated 1996. Although VAU is a relatively common condition, the small number of patients recruited suggested the impracticability of conducting larger studies.

We found that oral acyclovir was significantly effective over placebo in the treatment of VZV anterior uveitis patients. However, we could not derive the same conclusion for the treatment of HSV anterior uveitis. In addition, we could not establish any significant superiority of one treatment over the other in the management of VZV anterior uveitis and herpes zoster ophthalmicus, including topical acyclovir compared to oral acyclovir or topical corticosteroids, and oral acyclovir compared to a different length of treatment or oral valaciclovir.

Several outcome measures including those on recurrences, duration of therapy, choice of antiviral therapies, and topical/systemic routes of administration could not be assessed since there is lack of data in the published literature. Hence, only narrative review could be performed for these data points. Therefore, currently, the treatment of HSV and VZV anterior uveitis may be based on individual experiences and limited literature, largely due to weak clinical trial literature in this 


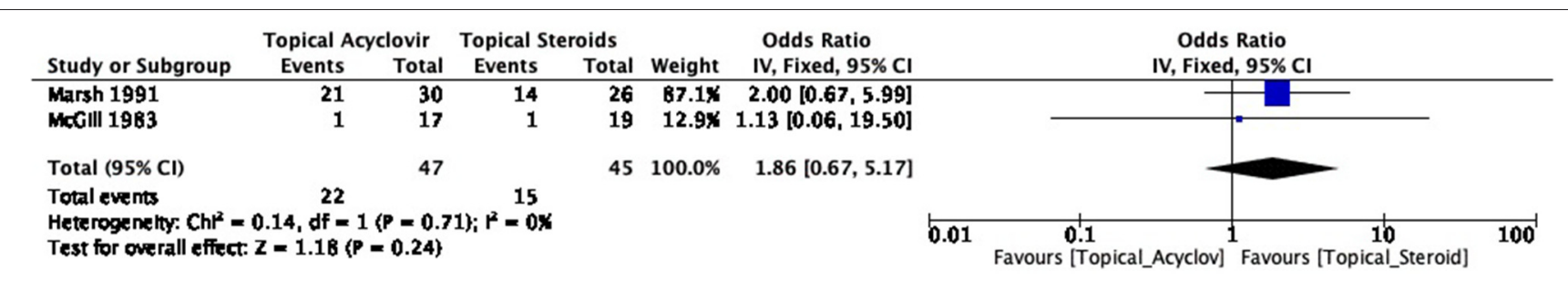

FIGURE 6 | Forest plot comparing treatment failure in varicella zoster virus anterior uveitis patients treated with topical acyclovir vs. topical corticosteroids.

TABLE 4 | Recurrences and Adverse reactions.

\begin{tabular}{|c|c|c|c|}
\hline $\mathbf{S} / \mathbf{N}$ & References & Recurrences & Adverse reactions \\
\hline 1 & $\begin{array}{l}\text { The Herpetic Eye Disease } \\
\text { Study Group (20) }\end{array}$ & $\begin{array}{l}33.3 \% \text { in oral acyclovir treated group; } 22.2 \% \text { in placebo } \\
\text { treated group }\end{array}$ & $\begin{array}{l}4.5 \% \text { in oral acyclovir treated group; } 0 \% \text { in placebo } \\
\text { treated group }\end{array}$ \\
\hline 2 & Wilhelmus etal. (23) & Not reported & Not reported \\
\hline 3 & Marsh and Cooper (18) & $\begin{array}{l}18.7 \% \text { in the topical acyclovir treated group; } 31.8 \% \text { in topical } \\
\text { corticosteroids treated group; } 34.6 \% \text { in topical acyclovir and } \\
\text { topical corticosteroids treated group }\end{array}$ & Not reported \\
\hline 4 & McGill and Chapmen (19) & $\begin{array}{l}0 \% \text { in topical acyclovir treated group; } 63 \% \text { in topical } \\
\text { corticosteroids treated group }\end{array}$ & Not reported \\
\hline 5 & Cobo et al. (13) & Not reported & Not reported \\
\hline 6 & Colin et al. (14) & Not reported & $\begin{array}{l}14.8 \% \text { in oral acyclovir treated group; } 0 \% \text { in oral } \\
\text { valaciclovir treated group }\end{array}$ \\
\hline 7 & Harding and Porter (15) & Not reported & $\begin{array}{l}52.1 \% \text { in oral acyclovir treated group; } 0 \% \text { in } \\
\text { placebo group }\end{array}$ \\
\hline 8 & Hoang-Xuan et al. (16) & Not reported & $\begin{array}{l}17.1 \% \text { in } 7 \text { day course oral acyclovir group; } 13.3 \% \\
\text { in } 14 \text { day course group }\end{array}$ \\
\hline 9 & Neoh et al. (17) & Not reported & Not reported \\
\hline
\end{tabular}

regard. Since VZV anterior uveitis is traditionally regarded to be more severe, antiviral therapy is routinely recommended in addition to anti-inflammatory therapy (28). In HSV anterior uveitis, further research is needed in clearly defining the role of antiviral therapy as observed from our meta-analysis. As there were no more than two RCTs included in the study to compare the same treatment approach, the efficacy of one treatment over another could not be conclusively established. In addition, even though effort has been made in the past to assess and compare different treatment approaches, our study identified a huge research gap, since no data have been published over the last 20 years. The results of this study will guide the research questions of future. We would hope that such trials will address the research gap, and rigorously evaluate the efficacy of different antiviral therapies in the treatment of VAU.

Limitations of the study include selection, performance, detection and reporting bias, with most study defined at unclear risk of bias. There was also a lack of data available in the full text from some of the studies included, such as details of the drugs administered, and their duration. Due to these factors, there is a lot of confusion in the ophthalmic community regarding the type of antiviral drug and the duration of antiviral and corticosteroid therapy that is optimum for patients diagnosed with VAU. There is a need for prospective studies to establish evidence-based guidelines for the management of this condition. Further, there is limited data on the management of complications of VAU such as glaucoma, cataract and other issues such as the role of PCR. None of the patients in the enrolled studies had confirmation of the viral agent using PCR from ocular fluids. In the current era, PCR detection of the type of viral agent is considered to be the standard of care. This represents a major limitation in the analysis.

In conclusion, from our research, it emerged that the current management of VAU is based on weak evidence and robust clinical data especially on therapeutics is needed. As a result, the ophthalmic fraternity is still unable to ask the question: how best do I manage a patient with VAU? In this regard, a multicentre approach would be beneficial in establishing treatment guidelines. Our study group has initiated a multicentre collaborative effort-The Infectious Uveitis Treatment Algorithm Network (TITAN)-aimed at establishing evidence and experience based guidelines for the management of patients with intraocular infectious diseases, including VAU. The collaborative efforts will look at establishing treatment algorithms for the management of anterior uveitis secondary to HSV and VZV through extensive literature review and collation of uveitis expert opinions from around the world. It is our hope these guidelines will serve as an important resource for clinicians managing patients with VAU. 


\section{DATA AVAILABILITY STATEMENT}

The original contributions presented in the study are included in the article/Supplementary Material, further inquiries can be directed to the corresponding author.

\section{AUTHOR CONTRIBUTIONS}

VG, CP, RA, MW, and S-PC contributed to conception and design of the study. NJ, ND, AAh, MD, and AK performed the statistical analysis. IT and KA wrote the first draft of the manuscript. AAg, ZT, and SL wrote sections of the manuscript. All authors contributed to manuscript revision, read, and approved the submitted version.

\section{REFERENCES}

1. Zandi S, Bodaghi B, Garweg JG. Review for disease of the year: treatment of viral anterior uveitis: a perspective. Ocul Immunol Inflamm. (2018) 26:113542. doi: 10.1080/09273948.2018.1498109

2. Cunningham ET Jr. Diagnosing and treating herpetic anterior uveitis. Ophthalmology. (2000) 107:2129-30.

3. Siverio Júnior CD, Imai Y, Cunningham ET Jr. Diagnosis and management of herpetic anterior uveitis. Int Ophthalmol Clin. (2002) 42:43-8. doi: 10.1097/00004397-200201000-00007

4. Jap A, Chee SP. Viral anterior uveitis. Curr Opin Ophthalmol. (2011) 22:4838. doi: 10.1097/ICU.0b013e32834be021

5. Chronopoulos A, Roquelaure D, Souteyrand G, Seebach JD, Schutz JS, Thumann G. Aqueous humor polymerase chain reaction in uveitis - utility and safety. BMC Ophthalmol. (2016) 16:189. doi: 10.1186/s12886-016-0369-z

6. Schacher S, Garweg JG, Russ C, Böhnke M. Diagnosis of herpetic uveitis and keratouveitis. Klin Monatsbl Augenheilkd. (1998) 212:359362. doi: 10.1055/s-2008-1034906

7. Shoughy SS, Alkatan HM, Al-Abdullah AA, El-Khani A, De GrootMijnes JD, Tabbara KF. Polymerase chain reaction in unilateral cases of presumed viral anterior uveitis. Clin Ophthalmol. (2015) 14:23258. doi: 10.2147/OPTH.S93655

8. Laaks D, Smit DP, Harvey J. Polymerase chain reaction to search for Herpes viruses in uveitic and healthy eyes: a South African perspective. Afr Health Sci. Sep. (2015) 15:748-54. doi: 10.4314/ahs.v15i3.7

9. Atherton SS, Pesicka GA, Streilein JW. Retinitis and deviant immune responses following intravitreal inoculation of HSV-1. Invest Ophthalmol Vis Sci. (1987) 28:859-66.

10. Pleyer U, Chee SP. Current aspects on the management of viral uveitis in immunocompetent individuals. Clin Ophthalmol. Jun. (2015) 5:101728. doi: 10.2147/OPTH.S60394

11. Büchi ER, Herbort CP, Ruffieux C. Oral acyclovir in the treatment of acute herpes zoster ophthalmicus. Am J Ophthalmol. (1986) 102:5312. doi: 10.1016/0002-9394(86)90086-3

12. Cobo LM, Foulks GN, Liesegang T, Lass J, Sutphin J, Wilhelmus $\mathrm{K}$, et al. Oral acyclovir in the therapy of acute herpes zoster ophthalmicus. An interim report. Ophthalmology. (1985) 92:157483. doi: 10.1016/S0161-6420(85)33842-3

13. Cobo LM, Foulks GN, Liesegang T, Lass J, Sutphin JE, Wilhelmus K, et al. Oral acyclovir in the treatment of acute herpes zoster ophthalmicus. Ophthalmology. (1986) 93:763-70. doi: 10.1016/S0161-6420(86)33678-9

14. Colin J, Prisant O, Cochener B, Lescale O, Rolland B, Hoang-Xuan T. Comparison of the efficacy and safety of valaciclovir and acyclovir for the treatment of herpes zoster ophthalmicus. Ophthalmology. (2000) 107:150711. doi: 10.1016/S0161-6420(00)00222-0

\section{FUNDING}

This work was supported by the National Institute for Health Research (NIHR) Biomedical Research Center based at Moorfields Eye Hospital NHS Foundation Trust and UCL Institute of Ophthalmology. The views expressed are those of the authors and not necessarily those of the NHS, the NIHR or the Department of Health.

\section{SUPPLEMENTARY MATERIAL}

The Supplementary Material for this article can be found online at: https://www.frontiersin.org/articles/10.3389/fmed. 2021.686427/full\#supplementary-material

15. Harding SP, Porter SM. Oral acyclovir in herpes zoster ophthalmicus. Curr Eye Res. (1991) 10(Suppl):177-82. doi: 10.3109/02713689109020376

16. Hoang-Xuan T, Büchi ER, Herbort CP, Denis J, Frot P, Thénault S, et al. Oral acyclovir for herpes zoster ophthalmicus. Ophthalmology. (1992) 99:1062-70; discussion 1070-1. doi: 10.1016/S0161-6420(92)31849-4

17. Neoh C, Harding SP, Saunders D, Wallis S, Tullo AB, Nylander A, et al. Comparison of topical and oral acyclovir in early herpes zoster ophthalmicus. Eye. (1994) 8 (Pt 6):688-91. doi: 10.1038/eye.1994.170

18. Marsh RJ, Cooper M. Double-masked trial of topical acyclovir and steroids in the treatment of herpes zoster ocular inflammation. Br J Ophthalmol. (1991) 75:542-6. doi: 10.1136/bjo.75.9.542

19. McGill J, Chapman C. A comparison of topical acyclovir with steroids in the treatment of herpes zoster keratouveitis. Br J Ophthalmol. (1983) 67:74650. doi: 10.1136/bjo.67.11.746

20. The Herpetic Eye Disease Study Group. A controlled trial of oral acyclovir for iridocyclitis caused by herpes simplex virus. Arch Ophthalmol. (1996) 114:1065-72. doi: 10.1001/archopht.1996.01100140267 002

21. Herpetic Eye Disease Study Group. Acyclovir for the prevention of recurrent herpes simplex virus eye disease. N Engl J Med. (1998) 339:3006. doi: 10.1056/NEJM199807303390510

22. Miserocchi E, Modorati G, Galli L, Rama P. Efficacy of valacyclovir vs acyclovir for the prevention of recurrent herpes simplex virus eye disease: a pilot study. Am J Ophthalmol. (2007) 144:547-51. doi: 10.1016/j.ajo.2007.06.001

23. Wilhelmus KR, Dawson CR, Barron BA, Herpetic Eye Disease Study Group. Risk factors for herpes simplex virus epithelial keratitis recurring during treatment of stromal keratitis or iridocyclitis. Br J Ophthalmol. (1996) 80:96972. doi: 10.1136/bjo.80.11.969

24. The Herpetic Eye Disease Study Group. A controlled trial of oral acyclovir for the prevention of stromal keratitis or iritis in patients with herpes simplex virus epithelial keratitis. The Epithelial Keratitis Trial. Arch Ophthalmol. (1997) 115:703-12. doi: 10.1001/archopht.1997.01100150 705001

25. Szeto SK, Chan TC, Wong RL, Ng AL, Li EY, Jhanji V. Prevalence of ocular manifestations and visual outcomes in patients with herpes zoster ophthalmicus. Cornea. (2017) 36:338-42. doi: 10.1097/ICO.0000000000001046

26. Hoang-Xuan T, Frot P, Denis J, Pouliquen Y. Aciclovir et trifluorothymidine dans la kérato-uvéite herpétique. Une étude comparative en clinique humaine. Indications de la corticothérapie [Acyclovir and trifluorothymidine in herpetic kerato-uveitis. A comparative clinical study. Indications for corticoid therapy]. J Fr Ophtalmol. (1984) 7:125-31.

27. Schuster AK, Harder BC, Schlichtenbrede FC, Jarczok MN, Tesarz J. Valacyclovir versus acyclovir for the treatment of herpes zoster ophthalmicus 
in immunocompetent patients. Cochrane Database Syst Rev. (2016) 11:CD011503. doi: 10.1002/14651858.CD011503.pub2

28. Babu K, Konana VK, Ganesh SK, et al. Viral anterior uveitis. Indian $J$ Ophthalmol. (2020) 68:1764-73. doi: 10.4103/ijo.IJO_928_20

Conflict of Interest: The authors declare that the research was conducted in the absence of any commercial or financial relationships that could be construed as a potential conflict of interest.
Copyright (๐ 2021 Testi, Aggarwal, Jaiswal, Dahiya, Thng, Agarwal, Ahuja, Duggal, Kankaria, Ling Ho, Chee, Westcott, Pavesio, Agrawal and Gupta. This is an openaccess article distributed under the terms of the Creative Commons Attribution License (CC BY). The use, distribution or reproduction in other forums is permitted, provided the original author(s) and the copyright owner(s) are credited and that the original publication in this journal is cited, in accordance with accepted academic practice. No use, distribution or reproduction is permitted which does not comply with these terms. 